\title{
Effectiveness of Self-Management Education based on Information Technology (IT) in Chronic Kidney Disease Patients
}

\section{Innani Wildania Husna, Qolbi Nur Qoidah Yahya, Masita Widiyani, and Sholihin Sholihin}

Faculty of Nursing, Universitas Airlangga, Surabaya, Indonesia

\begin{abstract}
Introduction: Chronic Kidney Disease (CKD) has a slow progression in the treatment process. The use of IT (information technology) media as an innovation to support health education in patients with chronic kidney failure to improve their knowledge and self-management nowadays is becoming a trend.

Methods: We analyzed the literature to identify the effectiveness of IT using as education media on chronic kidney disease patients. Articles were obtained by PRISMA approach from Scopus, ScienceDirect, CINAHL, PubMed, and Proquest limited to the 5 years; from 2013 to 2018 and obtained 12 articles with RCTs design study. We identified interventions based on IT devices such as smartphones, PDAs (Personal Digital Assistant), computer-based applications, telehealth, film, SMS, and website-based applications.
\end{abstract}

Results: This studies assessed 12 journals. According to the outcomes, there were 38 outcomes in total which are divided into three groups. They were 13 clinical outcomes, 14 caring process outcomes, and 11 usability and feasibility outcomes.

Conclusion: Overall, the percentage of intervention which had a positive effect on the outcomes was about 47\%. Smartphone and computer-based technologies are the most effective to help the patient find information about aspects related to caring, self and disease management which are recommended by the health care team.

\section{ARTICLE HISTORY}

Received: Dec 26, 2019

Accepted: Dec 31, 2019

\section{KEYWORDS}

chronic kidney disease; selfmanagement; computer-based technologies; caring

\section{CONTACT}

Innani Wildania Husna $\triangle$ innani.wildania.husna2018@fkp.unair.ac.id

$\equiv$ Faculty of Nursing, Universitas Airlangga, Surabaya, Indonesia

Cite this as: Husna, I. W., Yahya, Q.N.Q., Widiyani, M., \& Sholihin, S. (2019). Effectiveness of Self-Management Education based on Information Technology (IT) in Chronic Kidney Disease Patients. Jurnal Ners, 14(3si), 397-401. doi:http://dx.doi.org/10.20473/in.v14i3(si).17180

\section{INTRODUCTION}

Chronic Kidney Disease (CKD) is associated with agerelated kidney function accelerated in hypertension, diabetes, and obesity. CKD is a prolonged disease that affects $13.4 \%$ of the population worldwide, with indicators of damage to the results of kidney imaging or marked by proteinuria and decreased kidney function (Glomerulus Filter Rate / GFR lower than serum creatinine). Poor treatment of CKD causes kidney failure that requires expensive treatments such as dialysis or transplantation (Asl, Lakdizaji, Ghahramanian, \& Seyedrasooli, 2018).

Repairing CKD is very slow, so it requires health education to be able to self-managed from patients and routine monitoring of blood sugar, physical activity, eating and drinking patterns, and compliance with taking medicines (Barahimi et al., 2017). Improved information technology as a means of health education has developed at this time, Information Technology (IT) based interventions help improve health information and help communication with health care providers so as to be able to help patients in self-management (Diamantidis et al., 2015).

New technology is increasingly developing with the many media applications for health information for patients via the internet and smartphones, such as SMS services, video conferencing, telephone contacts. It offers an understanding of the disease and a good way of self-management (Diamantidis et al., 2012).

This review explores IT media as an innovation supporting education to inform, engage and 
communicate with patients suffering from kidney failure so that patients are able to improve their knowledge and self-management. There are many effective interventions to improve self-management in CKD patients by using IT media, but some do not provide positive results. Although health education through IT can improve patient self-management, there are some disadvantages to using IT media, namely indirect discussion between patients with experts, limited communication, and human error. There is no systematic review that explains the most effective IT media to improve self-management in CKD patients. Several questions have been evaluated from several articles: what type of intervention is given? What are the uses for each media? What are the results of the intervention? And what are the most effective media used to improve self-management in CKD patients?

\section{MATERIALS AND METHODS}

We focus our analysis on studies which evaluate the effectiveness of information technology to increase self-management on a patient with chronic kidney disease because media intervention has positive effect interventions and negative effect interventions.

\section{Data Source and Strategy}

We use four steps to identify and select articles that meet the criteria specified in this review. First, a comprehensive search was conducted at Scopus, Science Direct, CINAHL, PubMed, and Proquest to identify relevant research published in the last 5 years (2013-2018). Search strategies include using combinations related to information technology (such as smartphone, mobile application, website, telehealth, e-learning, and the internet) and also kidney disease (such as chronic kidney failure, dialysis). The second, screening articles, we read each title and abstract and focus on three main criteria: the articles population is patients with chronic kidney failure stage 1-5, the articles focus on effectiveness of information technology for health education to increase self-management, the articles report the result of self-management on chronic kidney disease (CKD). The third, to identify eligible articles that include the criteria required and are read and understood to consider further inclusion criteria. In detail the articles must be: IT-based interventions in patients with stage 1 to 5 chronic kidney disease (CKD), more than 18 years of age, patient can apply all type of IT-based tools, such as mobile phones, tablets, computers, internet, web cameras that support intervention, design of randomized controlled trial (RCT) studies, and patient have control groups that accept health education standards without IT system. The exclusion criteria in the study were intervention studies with the direct involvement of health care providers with patients (telephone, SMS, and direct email) and the study that did not compare between groups, study protocols, before and after trials.

Last, articles are considered to be eligible for review and analysis. All of them focus on the

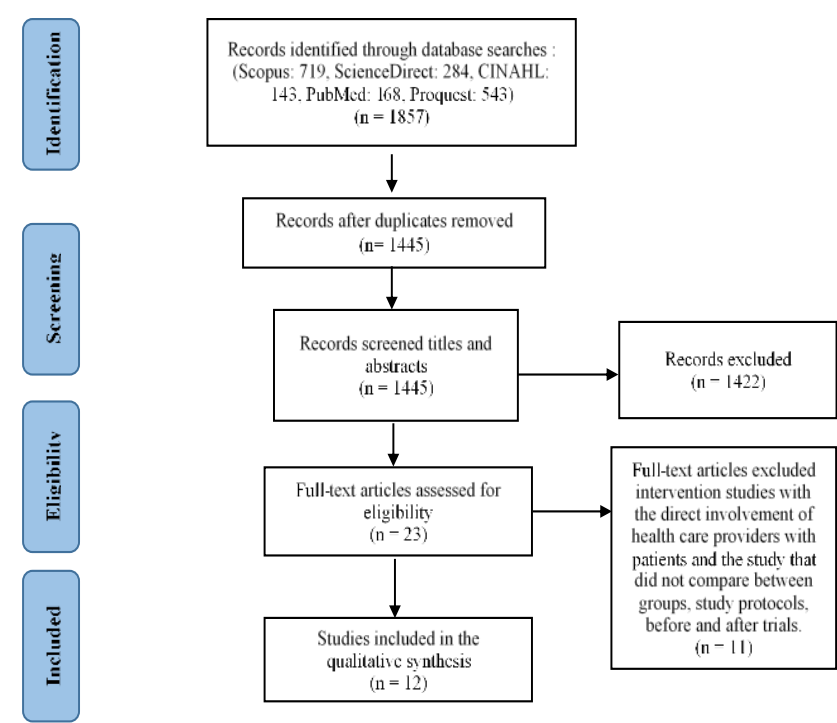

effectiveness of information technology health

Figure 1: Flowchart of the study selection process

education to increase self-management on the patient with chronic kidney disease.

\section{Article Analysis}

For each article that meets the requirements. The process of nursing outcomes affects patients with the increasing provision of health care information and interactions between patients and the health team. According to research (Elliott et al., 2016) interventions are classified as follows: a smartphone or digital device (application / SMS) used to provide information from a health care provider, devices that can be used to assess health according to independence (such as weight scales, BP monitors), computerized systems: information systems provided by patients via the internet or devices to healthcare providers. The results of the interventions were classified into four parts: statistically significantly positive, positive without statistical arguments, no statistical influence, and mixed effects (positive and non-effect).

\section{RESULTS}

\section{Study Selection}

A total of 1857 articles from initial searches were retrieved from various databases. Out of 1445 nonduplicate studies in the title and abstract screening process, 1422 studies were omitted due to lack of relevance. Of the remaining 23 studies, 12 met the eligibility criteria. Of 11 excluded studies because haven't control groups that accept health education without an IT media (Figure 1).

\section{Effects of Intervention on the Outcomes}

This systematic review assessed 12 articles that have outcomes for health education (Table 1). Table 2 shows the effects of the intervention on the outcome in the included studies. According to the outcomes, there were 38 outcomes in total which are divided into three groups. They were 13 clinical outcomes, 14 
Table 1. List of outcome health education based on the information technology

\begin{tabular}{|c|c|}
\hline Article writer & Outcome \\
\hline $\begin{array}{l}\text { Kiberd et al (Forster, Allem, } \\
\text { Mendez, Qazi, \& Jennifer, } \\
\text { 2015) }\end{array}$ & $\begin{array}{l}\text { There were no statistically significant differences in the baseline HRQOL score for those } \\
\text { who participate in the Web-Based eHealth portal and those who don't }\end{array}$ \\
\hline $\begin{array}{l}\text { Ong et al (He, Liu, Li, Wu, \& } \\
\text { Liu, 2016) }\end{array}$ & Increased level of patient compliance given the schedule of taking medication \\
\hline $\begin{array}{l}\text { Diamantidis et al (Heapy et } \\
\text { al., 2015) }\end{array}$ & $\begin{array}{l}\text { Patient satisfaction in accessing and obtaining information from the "Safe Kidney Care" } \\
\text { website }\end{array}$ \\
\hline Lee 0 et al (Hill et al., 2016) & $\begin{array}{l}\text { Increased patient satisfaction in e-PROM (Patient Reported Outcome Measures) against } \\
\text { HRQOL }\end{array}$ \\
\hline $\begin{array}{l}\text { Diamantidis et al (Ishani et } \\
\text { al., 2016) }\end{array}$ & Increasing patient knowledge about the safe use of drugs in mobile-based CKD patients \\
\hline $\begin{array}{l}\text { Asl et al (Jeddi \& Nabovati, } \\
\text { 2017) }\end{array}$ & $\begin{array}{l}\text { There was no difference in QOL between the messaging groups and face to face, a significant } \\
\text { increase in knowledge in the group face to face }\end{array}$ \\
\hline $\begin{array}{l}\text { Barahimi et al (Kiberd et al., } \\
\text { 2018) }\end{array}$ & Changes in serum high-density lipoprotein levels \\
\hline Elliott et al (Lee et al., 2018) & Satisfaction in the intervention group uses an online wiki \\
\hline $\begin{array}{l}\text { Sevick et al (Murali, Arab, } \\
\text { Vargas, \& Rastogi, 2013) }\end{array}$ & Controlling body weight and fluid \\
\hline Ishani et al (Ong et al., 2016) & $\begin{array}{l}\text { Able to control blood pressure, proteinuria, DM, fluid volume status, lipid levels, depression, } \\
\text { and patient activity }\end{array}$ \\
\hline $\begin{array}{l}\text { Murali et al (Sevick et al., } \\
\text { 2017) }\end{array}$ & $\begin{array}{l}\text { CKD patients have high motivation and desire to use the application. Knowledge of diet and } \\
\text { adherence to K / DOQI guidelines for Sub-Optimal CKD patients }\end{array}$ \\
\hline $\begin{array}{l}\text { Forster et al (Vegesna, Tran, } \\
\text { Angelaccio, \& Arcona, 2017) }\end{array}$ & Increasing patient knowledge and behavior with telenovela design \\
\hline
\end{tabular}

caring process outcomes, and 11 usability and feasibility outcomes. Overall, the percentage of intervention which had a positive effect on the outcomes was about $47 \%$. Otherwise, the percentage of intervention which had no significant effect on the outcomes was about $56 \%$.

\section{Clinical Outcomes}

The total clinical outcomes which are summarized on some studies had eight outcomes. They were Hemoglobin (one study), GFR (one study), Hba1c (one study), Lipoprotein (one study), triglyceride (one study), weight (two studies), waist size (one study), BMI (one study), MAP (one study), Serum Phosphate (one study) and Blood pressure (two studies), whereas the most commonly studied outcome was weight $(n=2)$. For overall, the percentage of clinical outcomes which resulted from positive effects from given intervention was $31 \%(n=4)$. The percentage of clinical outcomes which resulted in no significant effect from given intervention was $69 \%(n=9)$. For the type of intervention most used in studies and could result from a positive effect on the clinical outcome was a smartphone $(n=2)$. Otherwise, the website based intervention did not give a significant effect on the clinical outcome $(n=7)$.

\section{Caring Process Outcomes}

In the caring process, there were ten outcomes assessed. Those ten outcomes were knowledge (four studies), dietary adherence (two studies), QOL (one study), HRQOL (one study), attitude tendency toward health (one study), drugs identification ability (one study), decreasing inpatient visit (one study), decreasing emergency unit visit (one study), decreasing professional nurse clinic visit (one study), homecare dialysis experience (one study). From its outcome, knowledge became the most studied outcome in some journals $(n=4)$. From overall outcomes, there was $28 \%(n=4)$ intervention which gave a positive effect to the participants while $71 \%$ $(n=10)$ of the intervention did not give any significant effect. From the total of $28 \%$ intervention which gave a positive effect, knowledge became the most effective outcome which is a taken effect toward the intervention $(100 \%, n=4)$. For the most effective intervention type, movie media became the most used intervention in the caring process outcome category. While website based media became the most ineffective intervention in some studies.

\section{Usability and Feasibility Outcomes}

In this outcome, there were five outcomes assessed. The most used outcome to measure the usability and feasibility was participant satisfaction toward the media intervention $(n=5)$. Overall, the percentage of outcome which results in a positive effect on the participant was $99 \%(n=10)$ and $1 \%$ did not result in a significant effect. For the media type can be accepted by participants and gives a lot of usefulness for them was computer-based media intervention.

\section{DISCUSSION}

Systematic Review conducted by groups regarding effective information technology is used to provide Health Promotion to CKD patients. Health Promotion based on information's technology has increased the patient's independence in controlling his condition 
while at home. At the journal review, we have done, our group focuses on three components, there are Clinical Outcome, Treatment Process Category, and Usability, and Feasibility Category.

The results of the study showed that IT intervention had a positive effect of $28 \%$ of the total studies. The positive effect was observed from the results of the treatment process, namely increasing the knowledge of CKD patients by using smartphones, films, text messages and website based (Forster et al., 2015; He et al., 2016; Jeddi \& Nabovati, 2017; Vegesna et al., 2017). Therefore, it can be concluded that ITbased interventions are appropriate interventions to increase knowledge in self-management in CKD patients. In this study, blood pressure and weight regulation are the most frequently considered in the self-management of CKD patients, and clinically ITbased interventions help patients regulate and control blood pressure and weight, so patients can improve their antihypertensive medication regimen and improve awareness of patients in a sense of control of blood pressure and weight (He et al., 2016; Ishani et al., 2016).

The study in this article states that the IT media used has the ease of access and understanding of information because patients do not need other skills in accessing the internet, only by reading can patients understand information (Ishani et al., 2016). The development of the current digital era using smartphones is an appropriate intervention to improve self-management skills, this is included in the strategy of increasing patient education resources. IT has recently become a trending issue in research, as did Ishani who provided information and self-management by controlling blood pressure, proteinuria, fluid volume status, lipid levels and patient activity (Ong et al., 2016).

\section{Strength of the Study}

The study had several strengths and limitations. The strengths include the extensive search strategy used, which led to the extraction of a large number of studies and therefore made the relevance of missing studies very small. Moreover, only RCTs were included in the study and other types of studies were not included.

\section{Implication for Practice}

This study shows that health promotion based on IT can lead to the independence of CKD patients in controlling their disease. Therefore, the use of information technology is recommended to be used in clinical settings to further empower patients and increase patient care for their disease.

\section{The implication for further research}

The result of research is required to develop features in smartphones, not only in Health Promotion, but also Health Prevention, and Health Intervention. For example making features: how to calculate and control fluid balance, complicating alarms, diets menu for CKD patients, and so on. Educational materials used can also be improved, for example, spiritual emotion or undergoing CKD with a smile on CKD disease.

The limitations in this study are the exclusion of studies presented not in full text, which means the potential loss of some relevant studies.

\section{CONCLUSION}

IT-based intervention for CKD client such as smartphone, PDA, computer-based application, telehealth, movie, SMS, and website based intervention could help patients to seek information about caring, self-management, and disease management recommended by the health care team. Good coordination and active involvement between clients, technology developer and healthcare team are also being the main point for the using of IT-based intervention. Application socialization should be actively encouraged not only for middle to the upper class but also middle to lower class. In addition, the client's willingness to access technology should be improved too. From the aspect of usefulness through a usability test, it can be concluded that the client could get a lot of benefit from the IT-based application.

\section{REFERENCES}

Asl, P. T., Lakdizaji, S., Ghahramanian, A., \& Seyedrasooli, A. (2018). Effectiveness of Text Messaging and Face to Face Training on Improving Knowledge and Quality of Life of Patients undergoing Hemodialysis: a Randomized Clinical Trial. Tabriz University of Medical Sciences, 7(2), 95-100. https://doi.org/10.15171/jcs.2018.015

Barahimi, H., Zolfaghari, M., Abolhassani, F., Foroushani, A. R., Mohammadi, A., \& Rajaee, F. (2017). E-Learning Model in Chronic Kidney Disease Management A Controlled Clinical Trial. 11(4), 280-285.

Diamantidis, C. J., Ginsberg, J. S., Yoffe, M., Lucas, L., Prakash, D., Aggarwal, S., ... Fink, J. C. (2015). Article Remote Usability Testing and Satisfaction with a Mobile Health Medication Inquiry System in CKD. 10. https://doi.org/10.2215/CJN.12591214

Diamantidis, C. J., Zuckerman, M., Fink, W., Hu, P., Yang, S., \& Fink, J. C. (2012). Article Usability of a CKD Educational Website Targeted to Patients and Their Family Members. 1553-1560. https://doi.org/10.2215/CJN.03690412

Elliott, M. J., Straus, S. E., Pannu, N., Ahmed, S. B., Laupacis, A., Chong, G. C., ... Hemmelgarn, B. R. (2016). A randomized controlled trial comparing in-person and wiki-inspired nominal group techniques for engaging stakeholders in chronic kidney disease research prioritization. BMC Medical Informatics and Decision Making, 1-12. https://doi.org/10.1186/s12911-0160351-y

Forster, M., Allem, J., Mendez, N., Qazi, Y., \& Jennifer, B. (2015). Evaluation of a telenovela designed to 
improve knowledge and behavioral intentions among Hispanic patients with end-stage renal disease in Southern California. 7858(November). https://doi.org/10.1080/13557858.2015.1007 119

He, T., Liu, X., Li, Y., Wu, Q., \& Liu, M. (2016). Remote home management for chronic kidney disease : A systematic review. $O(0), \quad 1-11$. https://doi.org/10.1177/1357633X15626855

Heapy, A. A., Higgins, D. M., Cervone, D., Wandner, L., Fenton, B. T., \& Kerns, R. D. (2015). SPECIAL TOPICS SERIES A Systematic Review of Technology-assisted Self-Management Interventions for Chronic Pain Looking Across Treatment Modalities. 31(6), 470-492. https://doi.org/10.1097/AJP.0000000000000 185

Hill, N. R., Fatoba, S. T., Oke, J. L., Hirst, J. A., Callaghan, A. O., Lasserson, D. S., \& Hobbs, F. D. R. (2016). Global Prevalence of Chronic Kidney Disease - A Systematic Review and Meta-Analysis. 1-18. https://doi.org/10.5061/dryad.3s7rd.Funding

Ishani, A., Christopher, J., Palmer, D., Otterness, S., Clothier, B., Nugent, S., \& Nelson, D. (2016). Original Investigation Telehealth by an Interprofessional Team in Patients With CKD: A Randomized Controlled Trial. 68(1), 41-49. https://doi.org/10.1053/j.ajkd.2016.01.018

Jeddi, F. R., \& Nabovati, E. (2017). Features and Effects of Information Technology-Based Interventions to Improve Self-Management in Chronic Kidney Disease Patients: a Systematic Review of the Literature. https://doi.org/10.1007/s10916017-0820-6

Kiberd, J., Khan, U., Stockman, C., Radhakrishnan, A., Phillips, M., Kiberd, B. A., ... Tennankore, K. K. (2018). Effectiveness of a Web-Based eHealth Portal for Delivery of Care to Home Dialysis
Patients : A Single-Arm Pilot Study. https://doi.org/10.1177/2054358118794415

Lee, O., Kyte, D., Cockwell, P., Marshall, T., Dutton, M., Walmsley-allen, N., ... Calvert, M. (2018). Development and usability testing of an electronic patient-reported outcome measure ( ePROM ) system for patients with advanced chronic kidney disease. Computers in Biology and Medicine, 101(August), 120-127. https://doi.org/10.1016/j.compbiomed.2018.0 8.012

Murali, S., Arab, L., Vargas, R., \& Rastogi, A. (2013). Internet-Based Tools to Assess Diet and Provide Feedback in Chronic Kidney Disease Stage IV : Journal of Renal Nutrition, 23(2), e33-e42. https://doi.org/10.1053/j.jrn.2012.05.001

Ong, S. W., Jassal, S. V, Miller, J. A., Porter, E. C., Cafazzo, J. A., Seto, E., ... Logan, A. G. (2016). Article Integrating a Smartphone - Based Self Management System into Usual Care of Advanced CKD.

1-9. https://doi.org/10.2215/CJN.10681015

Sevick, M. A., Woolf, K., Mattoo, A., Sierra, A., Williams, S. K., \& Goldfarb, D. S. (2017). The Healthy Hearts and Kidneys (HHK) study: Design of a $2 \times 2$ RCT of technology-supported self-monitoring and social cognitive theory-based counseling to engage overweight people with diabetes and chronic kidney disease in multiple lifestyle changes. 64, 265-273.

https://doi.org/https://doi.org/10.1016/j.cct. 2017.08.020

Vegesna, A., Tran, M., Angelaccio, M., \& Arcona, S. (2017). Remote Patient Monitoring via NonInvasive Digital Technologies: A Systematic Review. Telemedicine and E-Health, 23(1), 3-17. https://doi.org/10.1089/tmj.2016.0051 